\title{
Have we become so accustomed to being passive that we've forgotten how to be active?
}

\author{
Jan Shield
}

In the theory of injury prevention, whether you subscribe to the school that espouses active strategies or the one that prefers the passive approach, it often seems to be a choice between irreconcilable differences.

Legislative and environmental changes are the key principles of the passive approach, while education and behaviour change are the cornerstones of the active approach.

When did the school of thought that asserts the supremacy of passive approaches come into being? Waller speaks of a 'conceptual shift' from attributing injuries to defective behaviour (requiring education to change that behaviour) to a reliance on environmental modifications. ${ }^{1}$ In fact, the passive approach was well entrenched by 1980 , when Baker wrote that 'measures that have proved most likely to work are those that never require any action by a child or his family', and that this protection is 'totally independent or the wisdom, caution, skill, and psychological makeup of the individuals who are protected'. ${ }^{2}$ Further, Baker notes that 'despite all the evidence that posters, pamphlets, media campaigns, and other educational programmes do not produce changes in daily behaviour that would effectively reduce injuries, this kind of approach is often relied upon'.

These views are reiterated by Wilson and colleagues who counsel that educating decision makers, although challenging, is less formidable than educating parents and children. ${ }^{3}$ This advice neglects the fact that many decision makers are subject to lobbying by powerful external forces that often influence whether safety makes it onto the agenda or not.

What do we mean by education, and does it work in health and safety promotion? Education can be directed to both individuals and populations. A 1981 UK case-control study concluded that health education did not reduce injuries, ${ }^{4}$ confirming the results of two earlier United States studies. The UK program used 'conventional health education techniques', that is leaflets, posters, and lectures, in one area of a small city. Data were collected for five weeks before the campaign and for nine weeks after. Not only was the sample very small and the time period short, the materials used were probably less sophisticated than those we may use today.

Robertson warns that some educational programs may actually do more harm than good. However, his principal, and certainly valid, criticism is that too many programs have been implemented without prior rigorous evaluation. ${ }^{5}$ Blanket disapproval of similar educational strategies may have been based on similarly scant evidence. No-one seems to have asked why they didn't work. Were they based on false premises or were there design problems in the studies?

Nevertheless, under the weight of a great deal of learned opinion that education doesn't work, you might be forgiven for wondering how you ever graduated from university and gained employment! Perhaps the point has been made so forcefully and so often that it has become a self fulfilling prophecy. What troubles those of us who believe that education has been undervalued and underutilised, is the sneaking suspicion that when the opportunitites for passive intervention run out, that leaves us with-yes, education and behaviour modification!

Other opinions acknowledge the role of education in 'creating a climate of opinion in which safety features in the product or the environment, or a particular safety action', ${ }^{\circ}$ and 'the need for flexibility in combining strategies to arrive at the most effective mix'.7 A comprehensive review of the role of education in injury prevention found many educational materials wanting, but that definitions of education were also too narrow. To be effective, educational approaches should be based on appropriate learning theory, applied to the right target audience, over a sufficient length of time, evaluated and then strongly promoted. ${ }^{8}$

There are several injury topics, for example food related choking, for which few passive interventions exist. Should these be ignored in favour of interventions where a product or an environmental modification might solve a problem? It is interesting to note that journal literature on such topics is sparse. I suggest that to ignore these topics borders on neglect. Parents are entitled to as much information as possible to protect their children and we should not be afraid to give it to them.

During the last few years, two highly successful health promotion campaigns have shown that education, appropriately targeted, could be effective on its own. These provide compelling evidence that community-wide education does work. The campaigns were the skin cancer campaign to reduce the incidence of melanomas in Australia, ${ }^{9}$ and the assault on sudden infant death (SIDS), which has spread world wide. ${ }^{10}$

Now that we have some models to follow, why hasn't injury prevention and control taken 
up the challenge? Perhaps some of us feel threatened by a change in emphasis, or maybe we don't understand the techniques of educational/behavioural approaches and feel uncomfortable with them. Most of us tend to seek the solutions we are most comfortable and familiar with-thus surgeons recommend surgery, engineers propose design changes, educators advocate teaching, and epidemiologists suggest that more data be collected!

The techniques of education and behaviour modification are certainly different from those of environmental change, and also are practised by different professional groups, many of whom don't speak the language of the other players. It is possible that those who espouse the passive approach might learn a great deal from those who've had to adapt to active approaches to achieve their objectives, and vice versa.

I'd like to suggest that we're in danger of becoming lazy (passive even?) in choosing those interventions that are 'easy' to do and neglecting those we consider too difficult. Of the 'three Es', education remains a key element. Without it enforcement and engineer- ing approaches cannot be effective. Before any countermeasures are implemented, politicians, injury control professionals, and the commu $\overline{2}$. nity, all need to be educated, influenced, ando bullied into supporting change. The key too using active strategies constructively is educa tion-we need to improve the education rathen than dismiss it.

1 Waller JA. Reflections on a half century of injury control Am F Public Health 1994; 84: 664-70.

2 Baker SP. Prevention of childhood injuries. Med f Ausţ

Ton MH, Baker SP, Teret SP, et al. Saving children. New York: Oxford University Press, 1991.

4 Minchom PE, Sibert JR, Newcombe RG, Bowley MA. Doeshealth education prevent childhood accidents? Postgraf Med f 1984; 60: 260-2.

5 Robertson LS. Injury epidemiology. New York: Oxford University Press, 1992.

6 Avery JG, Jackson RH. Children and their accidents. London. Edward Arnold, 1993.

7 National Committee for Injury Prevention and Controli Meeting the challenge. New York: Oxford University Press 1989.

8 Towner EML. The role of health education in childhood injury prevention. Injury Prevention 1995; 1: 53-8.

9 Hill D, White V, Marks R, Borland R. Changes in sun related attitudes and behaviours, and reduced sunburm prevalence in a population at high risk of melanoma. Eur Cancer Prev 1993; 2: 447-56.

10 Willinger $M$, Hoffman $H J$, Hartford RB. Infant sleep position and risk for sudden infant death syndrome Pediatrics 1994; 93: 814-9.

\title{
From educator to strategic activist for injury control
}

\author{
Elizabeth McLoughlin
}

The important question is not: are you for or against education to prevent injuries? The essential question is: what most effectively prevents a certain type of injury? My first 10 years working to prevent burns led me to believe that product and environmental modification to reduce the risk of injury was more effective than education about safe behaviors. As a teacher, this was a shift for me. I had started working as director of burn prevention at a pediatric burn unit in 1973, after earning a masters degree in education and teaching for seven years in classrooms from Head Start to adult evening college.

Several articles about our early prevention work highlight some of the lessons I learned. One article published in 1977 detailed a decrease in the number of children burned by sleepwear ignition who were admitted to our unit, coincident with the establishment of the children's flame resistant sleepwear standard. ${ }^{1}$ A pair of papers, published in 1982, concluded that a five year, $\$ 1$ million public education burn prevention program resulted in some knowledge gains among children participating in classroom activities, but had no measurable effect in reducing burn rates in metropolitan
Boston. ${ }^{23}$ Another, published in 1985, concluded that county legislation requiring resi dential smoke detectors resulted in mores homes being protected by working detectors, compared with a county without that require-윽 ment. Homes built after 1975, when buildings codes required 'hard-wired' detectors in al new construction, were more likely to havos working detectors regardless of county. Personal letters using threat or persuasion that were sent by fire chiefs to home owners failed to ${ }^{\omega}$ have a measurable effect on detector use. ${ }^{4}$ श्र

Environmental change is measurably effec운 tive in preventing injury. In addition to flame resistant sleepwear, examples include changing vacuum cleaner electrical cords to prevents mouth burns in toddlers, ${ }^{5}$ window guards too prevent childhood falls, ${ }^{6}$ the packaging of drugs, ${ }^{7}$ the design of safer cars, ${ }^{8}$ and of safer highways. ${ }^{9}$

The primary reason why we in public healtho should, whenever possible, focus on making environments rather than behaviors safer is thate environmental changes protect whole populations. Safe behaviors must be adopted individual by individual. They must be practised routinely, maintained over a lifetime, and be 